\title{
MODELO FRSAD COMO BASE PARA A REPRESENTAÇÃO TEMÁTICA NA DESCRIÇÃO ARQUIVÍSTICA'
}

\author{
Luciane Paula Vital* \\ Marisa Bräscher**
}

RESUMO

\begin{abstract}
A organização e representação da informação nos arquivos vêm ganhando espaço de discussão na literatura da Ciência da Informação, especialmente após a automatização dos sistemas de informação. Os modelos conceituais, apoiados na perspectiva entidade/ relacionamento, como os da família dos Functional Requirements (FR family), fornecem uma perspectiva para esse ambiente. Essa pesquisa considera que os documentos em arquivos apresentam especificidades, relacionadas à Organicidade e Proveniência que os diferenciam dos documentos em outros serviços de informação e, portanto, a representação temática desses documentos também apresenta peculariedades que devem ser consideradas. Esse estudo tem como objetivo estabelecer os themas para esses documentos, com base no modelo conceitual Functional Requiements for Subject Authority Data - FRSAD, da família FR. Apresenta como procedimentos metodológicos a pesquisa bibliográfica, para $\circ$ mapeamento e identificação das entidades representativas de assunto presentes nos modelos conceituais para Descrição Arquivística. Foram identificados cinco modelos conceituais, três deles apresentam entidades específicas para representar o conteúdo dos documentos. A partir do conjunto de entidades analisadas, chega-se ao 'Conceito/ Objeto', que representa a temática do documento e deriva da análise da Proveniência e da Organicidade, ou seja, do conjunto de entidades que as caracterizam, Agente, Função, Atividade, Data e Lugar. Conclui-se que os modelos conceituais para representação de assunto são pertinentes e colaboram no estabelecimento de múltiplas relações entre os conjuntos documentais em arquivos.
\end{abstract}

Palavras-chave: Modelos Conceituais. Representação temática. Descrição Arquivística. FRSAD
* Doutora em Ciência da Informação pela Universidade Federal de Santa Catarina, Brasil. Professora do Departamento de Ciência da Informação da Universidade Federal de Santa Catarina, Brasil.

E-mail: luciane.vital@ufsc.br.

** Doutora em Ciências da Informação pela Universidade de Brasília, Brasil. Docente permanente do Programa de Pós-graduação em Ciência da Informação da Universidade Federal de Santa Catarina, Brasil.

E-mail: marisa.brascher@ufsc.br.

\section{INTRODUÇÃO}

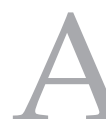

organização informação

e na

na Arquivologia

da desenvolvidas com maior ênfase nos processos de classificação e descrição. Neste

I Os resultados fazem parte de tese defendida no Programa de Pósgraduação em Ciência da Informação da Universidade Federal de Santa Catarina, Brasil. trabalho, interessa particularmente o processo de representação da informação que acontece por meio da descrição arquivística, atividade respaldada por uma norma internacional, a Internacional Standard Archival Description (ISAD (G), que serviu de base para o desenvolvimento de normas nacionais em diferentes países, entre eles o Brasil, com a Norma Brasileira de Descrição Arquivística (NOBRADE). 
A descrição arquivística é apresentada na ISAD (G) (INTERNATIONAL COUNCIL..., 2000, p.4) como um processo de representação das unidades de classificação arquivística que permite a identificação, gestão e o entendimento do contexto de produção dos conjuntos documentais e seus respectivos produtores.

A descrição é, portanto, um processo de organização e representação da informação apresentada nos documentos arquivísticos, que parte da análise e síntese para criar representações com vistas à gestão documental, com diferentes finalidades.

A organização e representação da informação nos arquivos vêm ganhando espaço de discussão na literatura da Ciência da Informação, especialmente após a automatização dos sistemas de informação. É necessário discutir e avançar na busca por referenciais teóricos que considerem as especificidades da área da Arquivologia. Um desses referenciais são os modelos conceituais, apoiados na perspectiva entidade/relacionamento, que se baseiam em modelos desenvolvidos em ambientes automatizados e apresentam a viabilidade de relacionamentos semânticos dinâmicos, como o exemplo da família dos Functional Requirements (FR family). Evidentemente, a aplicação de modelos de outras áreas deve levar em conta as especificidades do contexto arquivístico, como por exemplo, o fato de um documento ser o resultado de atividades e ações de uma instituição e servirem como prova dessas, além de manterem relações entre si que necessitam ser explicitadas, suas relações orgânicas e funcionais. Nos arquivos, mais que em outros serviços de informação, o contexto de produção dos documentos precisa ser definido e representado. Essa pesquisa considera que os documentos em arquivos apresentam especificidades que os diferenciam dos documentos em outros serviços de informação e, portanto, a representação temática desses documentos também apresenta peculariedades que devem ser consideradas a partir de estudos sobre esse tipo de representação em documentos arquivísticos.

Partindo da caracterização das especificidades da representação temática em arquivos, esse estudo tem como objetivo estabelecer os themas para esses documentos, com base no modelo conceitual Functional Requiements for Subject Authority Data (FRSAD), da família FR.
Para isso, além de considerar as especificidades dos documentos em arquivo, foram mapeadas as entidades e atributos relacionados à representação temática nos modelos conceituais para descrição arquivística (DA), tornando possível relacioná-las ao modelo FRSAD. Para o cumprimento desse objetivo foi realizada uma pesquisa bibliográfica no site do Conselho Internacional de Arquivos - ICA, com vistas a identificar os modelos conceituais existentes para DA e, nesses modelos, foram mapeadas as entidades e atributos que se relacionam à representação temática. Por fim, foi analisada a publicação desenvolvida pela International Federation of Library Associations and Institutions IFLA, que apresenta o modelo FRSAD completo, correlacionando as entidades identificadas com a estrutura conceitual e metodológica do modelo e com as características da descrição arquivística, o que possibilitou chegar a um conjunto de themas que podem ser úteis para caracterizar "sobre o que trata" um documento em arquivo.

\section{MODELOS CONCEITUAIS DA FAMÍLIA FR}

Especialmente influenciados pelos sistemas de informação automatizados, o aumento da produção bibliográfica e os custos do desenvolvimento de representações documentais, a Federação Internacional de Associações e Instituições Bibliotecárias (IFLA) buscou discutir princípios de padronização, no âmbito da representação descritiva e temática, dos registros bibliográficos. Primeiramente, a representação descritiva foi o foco principal, com o desenvolvimento dos Requisitos Funcionais para Registros Bibliográficos - Functional Requirements for Bibliographic Records (FRBR), que tem como objetivos:

\begin{abstract}
primeiro, fornecer um quadro estruturado, claramente definido, para relacionar dados registrados em registros bibliográficos, às necessidades dos usuários destes registros. $\mathrm{O}$ segundo objetivo é recomendar um nível básico de funcionalidade para registros criados por entidades bibliográficas nacionais. (IFLA, 1998, p. 7).
\end{abstract}

Os FRBR têm base no modelo entidaderelacionamento (E-R), o modelo E-R foi desenvolvido na década de 1970 por Peter 
Chen e é utilizado por muitos modelos teóricos de sistemas de informação. Para Chen (1977, p.78), "Uma entidade é uma "coisa" que pode ser claramente identificada. De acordo com as necessidades da empresa, entidades podem ser classificadas em diferentes tipos [...]" As entidades são conectadas umas às outras por meio de diferentes tipos de relacionamentos. Por exemplo, a entidade Documento e a entidade Arquivo podem estabelecer diferentes tipos de relacionamentos, como de pertencimento [no Arquivo há Documentos] e todo-parte [Documento faz parte do Arquivo]. Para Chen
(1977), os relacionamentos são estabelecidos de acordo com as características e necessidades do contexto onde o modelo está sendo desenvolvido e as entidades e relacionamentos têm propriedades que podem ser expressas por meio de atributos e valores [conteúdo é um atributo de Documento, que pode ser expresso por palavraschave].

No modelo E-R, as entidades são representadas por uma caixa retangular, os relacionamentos por losangos, os valores em círculos e os atributos por setas, como mostra a Figura 1.

\section{Figura 1: Modelo Entidade-Relacionamento}

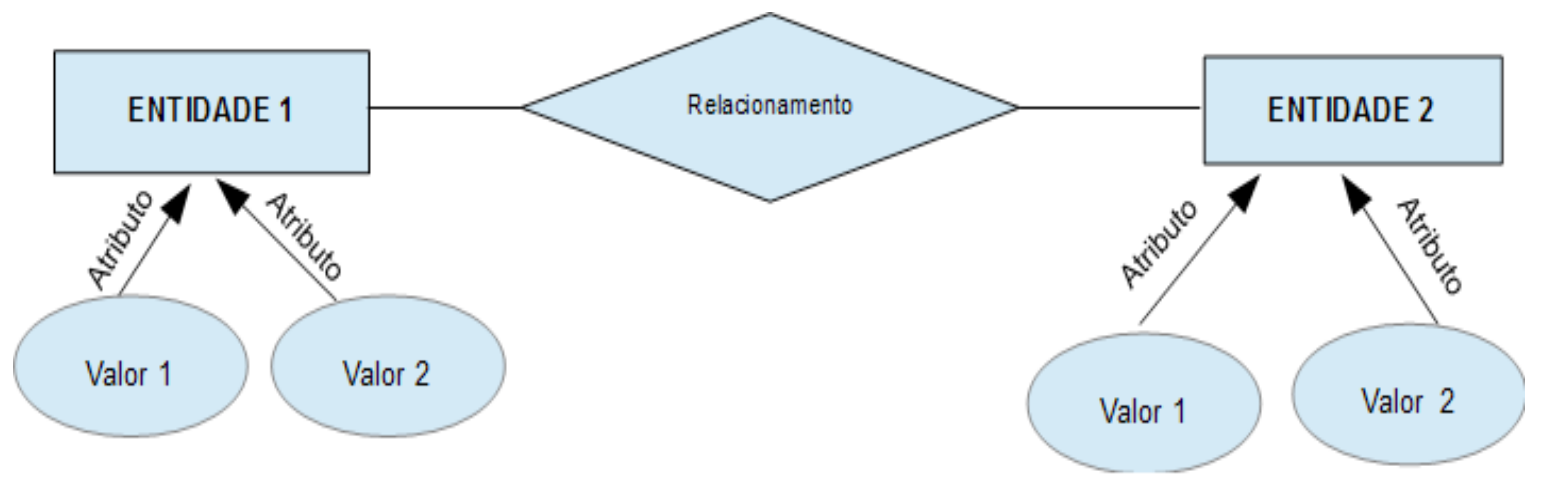

Fonte: Elaborado pelas autoras cCom base em Chen (1977)

Essa é a estrutura básica do modelo proposto por Chen, uma das características importantes, presente também nos modelos da International Federation of Library Associations and Institutions - IFLA, é o foco nos relacionamentos entre os registros de informação, o que abre possibilidades de interligações significativas do ponto de vista do interagente com o sistema, e possibilidades infinitas de combinações coerentes com o contexto dinâmico da informação digital.

Segundo Moreno e Arellano (2005, p.23) o modelo FRBR reestrutura os registros bibliográficos e considera as seguintes diversidades:

\footnotetext{
- usuários - usuários da biblioteca pesquisadores, bibliotecários da seção de aquisição, publicadores, editores, vendedores;

- materiais - textuais, musicais, cartográficos, audiovisuais, gráficos e tridimensionais;
}

- suporte físico - papel, filme, fita magnética, meios óticos de armazenagem, etc. e,

- formatos - livros, folhas, discos, cassetes, cartuchos, etc. que o registro possa conter.

Pensados no contexto das novas e variadas formas de acesso aos documentos, no formato digital, e em um usuário mais autônomo no processo de recuperação, os modelos conceituais objetivam construir o processo de representação na perspectiva de quem buscará a informação.

No desenvolvimento da família FR, foram criados modelos para aspectos específicos, divididos em três grupos e dez requisitos, ficando assim denominados:

Grupo1: Functional Requirements for Bibliographic Records- FRBR; Requisitos Funcionais: Obra, Expressão, Manifestação e Item; 
Grupo 2: Functional Requirements for Authority Data - FRAD; Requisitos Funcionais: Pessoa e Entidade coletiva, e;

Grupo 3: Functional Requirements for Subject Authority Data - FRSAD; Requisitos Funcionais : Conceito, Objeto, Evento e Lugar.

Cada modelo adotou diferentes pontos de vista e soluções, o conjunto dos grupos é denominado Família FR (RIVA; ZUMER, 2015), conforme ilustra a figura 2.

\section{Figura 2: Família FR}

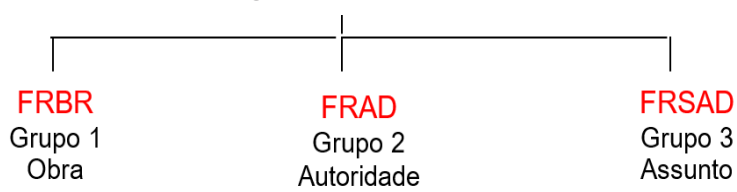

Fonte: elaboração do autor

Em 2010 a IFLA, em relação ao grupo 3 relativo à representação de assunto, publicou o Functional Requirements for Subject Authority Data (FRSAD). Como visto, os relacionamentos são fundamentais e responsáveis pela ligação entre as entidades, e se estabelecem no contexto de aplicação, como o modelo FRSAD desenvolve em relação ao assunto dos documentos, conforme descrito a seguir.

\section{I FRSAD}

O modelo FRSAD (IFLA, 2010, p.34) se propõe a fornecer suporte para as seguintes tarefas de usuários que buscam o acesso aos recursos informacionais pelo assunto:

- $\quad$ Encontrar: localizar um ou mais assunto e/ou denominações, com base nos critérios de busca dos usuários;
- $\quad$ Identificar: distinguir entre assuntos similares e/ou suas denominações;

- - Selecionar: entre os assuntos/ denominações encontradas, escolher aqueles que correspondem ao contexto e necessidade do usuário;

- $\quad$ Explorar: familiarizar-se com o sistema/ domínio e sua terminologia.

O modelo FRSAD identificou e definiu duas entidades de alto nível para os dados de autoridade de assunto, thema e nomen, sendo definidas assim (IFLA, 2010, p.15):

- Thema: qualquer entidade usada como um assunto de uma obra.

- Nomen: qualquer signo ou sequência de signos (caracteres alfanuméricos, símbolo, som, etc.) que um thema é conhecido por, referido a, ou tratado como.

Thema $e$ nomen são centrais no desenvolvimento do modelo FRSAD, o qual define que uma obra tem como assunto um thema, que é assunto de uma obra' assim como um thema tem denominação no nomen, e um nomen é a denominação de um thema, como mostra a Figura 3. A tematicidade de uma obra é estabelecida por infinitas possibilidades de relações (many-to-many ) entre obra (work), thema e nomen, entre themas, entre themas e nomen, e entre nomens. O grupo de trabalho, de acordo com IFLA (2010, p.16), escolheu os termos em latim, thema e nomen, "por não terem um significado pré-estabelecido no nosso contexto, por serem culturalmente neutros e não necessitar de tradução". Essas duas relações 'Tem como assunto' e 'Tem como denominação' são as principais relações entre Entidades do modelo FRSAD, e são 'many-tomany', ou seja, uma obra pode ter muitos themas, assim como um thema pode ser assunto de muitas obras, a figura 3 ilustra essas relações.

Figura 3: Modelo básico do FRSAD

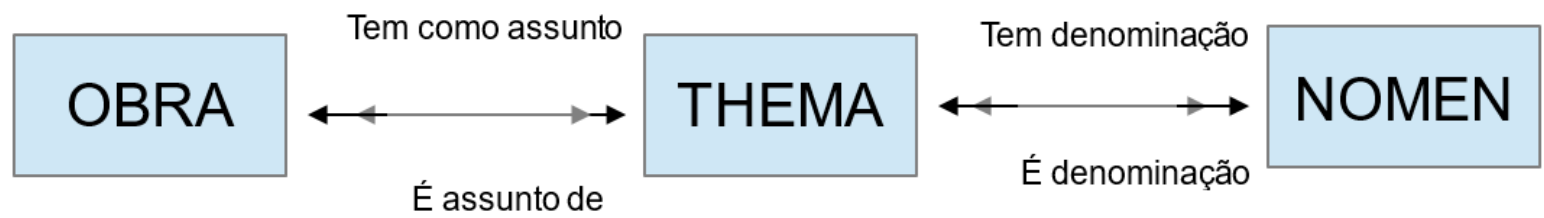

Fonte: Adaptado de IFLA (2010, p.15) 
A figura 4 mostra que os três grupos da família FR podem ser thema de uma obra, isto é, expressam sua temacidade e apresentam uma designação por meio de um nomen. Essa relação de themas é apresentada no modelo FRSAD apenas como exemplo que se aplica aos documentos bibliográficos.

Figura 4: Relação FRSAD com a família FR

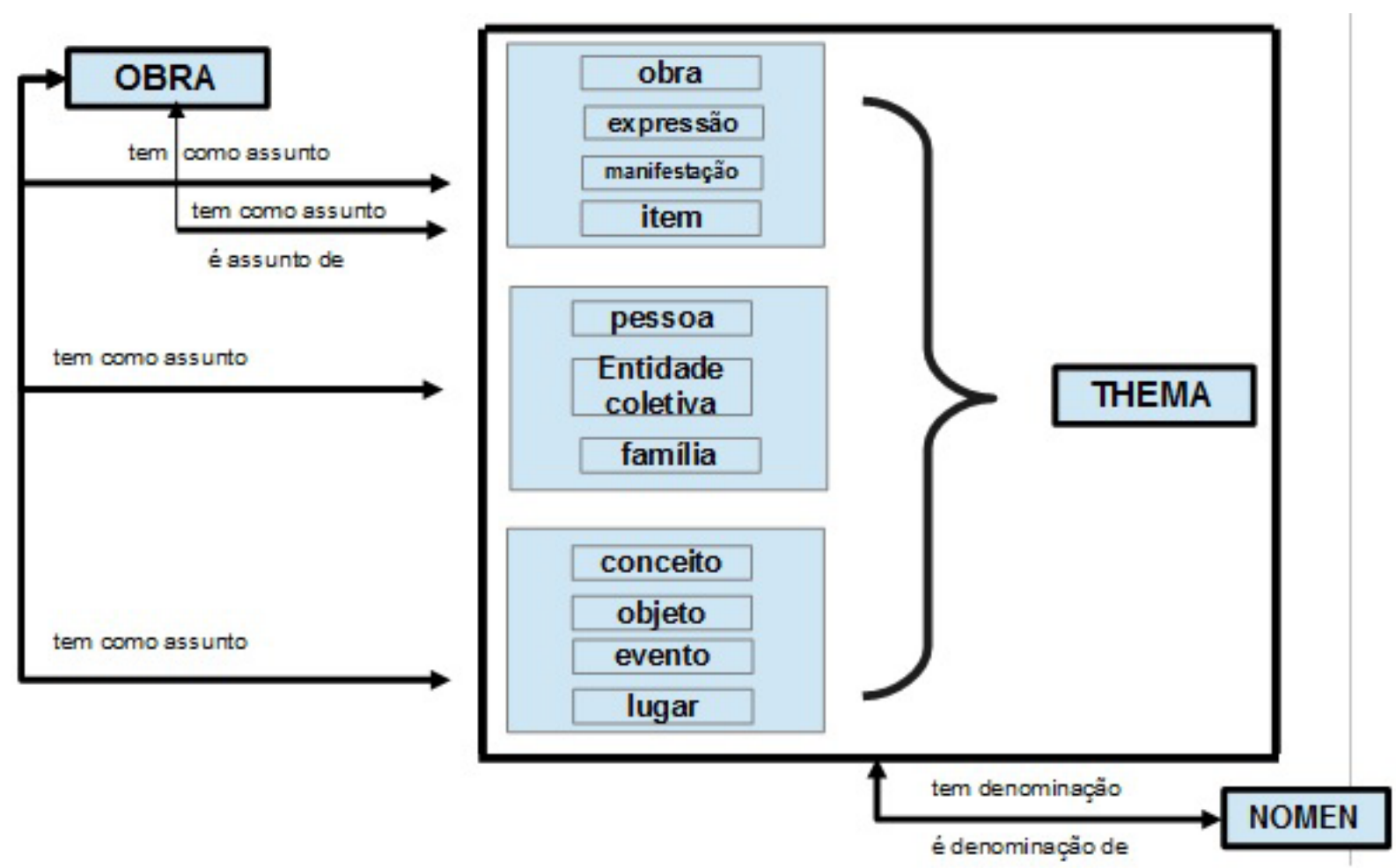

Fonte: Adaptado de IFLA (2010, p.15)

O modelo FRSAD apresenta a possibilidade de ser desenvolvido em qualquer contexto e com todos os tipos de registros documentais, o que nos leva ao tema desta pesquisa, sua aplicação na representação temática de documentos arquivísticos.

Melo (2013, p.84), ao identificar o pragmatismo no modelo FRSAD, ressalta que a incidência do pragmatismo no modelo
FRSAD representa a necessidade de
considerar a influência do contexto
cultural para a organização do
conhecimento. Nessa abordagem busca-
se o significado que há no uso dos
termos em um universo específico do
discurso. O conhecimento é analisado
em sua dimensão social, considerando
a dinâmica contextual e instável do
processo de comunicação entre indivíduos. A importância da abordagem pragmática consiste na possibilidade de construir uma estrutura contextual e flexível para a representação do conhecimento.

Em relação aos documentos arquivísticos, o pragmatismo presente no FRSAD oferece o espaço para o desenvolvimento de representações dinâmicas e flexíveis, abrangendo os contextos e especificidades que esses documentos apresentam. Com o intuito de apresentar de maneira resumida os principais aspectos dos modelos conceituais para Descrição Arquivística analisados nesta pesquisa, destacam-se na seção seguinte as Entidades de cada modelo, com ênfase para o entendimento sobre Assunto em cada um deles. 


\subsection{Modelos conceituais para descrição arquivística}

Os modelos conceituais na descrição arquivística não buscam discutir a atividade em si, tarefa realizada no âmbito das normas e diretrizes nacionais e internacionais. Um modelo conceitual para esse processo objetiva responder às novas exigências do contexto tecnológico e das dinâmicas da sociedade pós-moderna, e definem um conjunto de entidades e relacionamentos que podem ser tomados como base para o desenvolvimento de sistemas de arquivos.

Os modelos conceituais para descrição arquivística encontrados na literatura foram desenvolvidos pelos Arquivos Nacionais da Austrália, Nova Zelândia, Finlândia e Espanha, além do modelo do Conselho Internacional de Arquivos, em desenvolvimento. Apresentaremos as entidades de cada modelo e especificaremos as que se relacionam com a representação temática, foco desse estudo. Dos quatro modelos analisados, três deles, CMAD, CNEDA e RiC$C M$, apresentam uma entidade específica para representar o conteúdo do documento.

Os modelos Australian Government Recordkeeping Metadata Standard Version 2.0 (2008) (AGRkMS) e o Technical Specifications for the Electronic Recordkeeping Metadata Standard Version 1.0 (2008), do Arquivo da Nova Zelândia, foram projetados para serem usados como modelos de referência por instituições e profissionais da área de tecnologia no desenvolvimento de sistemas de informação para arquivos. Os dois modelos apresentam diferenças sutis e serão tratados conjuntamente, ambos desenvolveram um modelo de entidades-múltiplas com cinco entidades definidas: Documento, Agente, Função, Mandato e Relacionamentos. A partir das entidades definidas, apresentam os elementos e subelementos, em proposições de relações múltiplas, configurando-se em um modelo conceitual. Destacamos o Keyword, elemento não obrigatório, aplicado à entidade Documento, definido como "O assunto do documento ou as funções e atividades gerais e específicas da agência, que são documentadas no registro."(NATIONAL ARCHIVES (New Zealand), 2008, p.51). Essa definição aparece tanto no modelo da Nova Zelândia quanto no australiano, que apresentam como objetivos para esse elemento: facilitar a busca e recuperação da informação; classificar os documentos por assunto ou função; e documentar as relações entre os documentos e as funções/atividades que representam. Assim, as normas australiana e neozelandesa apresentam o assunto como um elemento da entidade Documento, salientando a importância para a busca e recuperação desses documentos e apontando que as funções e atividades registradas podem representar seu assunto.

O modelo desenvolvido na Finlândia, Finnish Conceptual Model for Archival Description - CMAD, teve sua versão preliminar publicada em 2013 (draft version) e é resultado do trabalho de um grupo de especialistas ligado ao Arquivo Nacional finlandês. Esse grupo tem como objetivo revisar os requisitos da descrição arquivística para atender aos novos sistemas de gestão e ambientes de arquivo, bem como explorar a base teórica desse processo (NATIONAL ARCHIVES (Finlândia), 2013). O modelo CMAD institui oito entidades: Função, Agente, Recurso de Informação, Evento do Ciclo de Vida, Mandato, Lugar, Evento Temporal e Assunto; a inclusão das três últimas é influência do modelo FR. Nesse modelo, o "Assunto representa qualquer tópico (conceitual ou físico) que o recurso tenha informação a respeito, mas não tem nenhuma relação contextual com o recurso de informação." (NATIONAL ARCHIVES (Finlândia), 2013, p.13). Afirma ainda que as entidades: Agente, Lugar e Evento Temporal e Assunto são internacionalmente reconhecidas como entidades-chave para a descrição de conteúdo de arquivo. Define a entidade Assunto (Subject) como, "Conceito ou objeto. Assuntos podem ser, por exemplo, filosofias, ideologias políticas, métodos, artefatos, processos, eventos, pessoas, áreas geográficas, construções ou organizações." (NATIONAL ARCHIVES (Finlândia), 2013, p.16). O CMAD entende que outras entidades do modelo conceitual também podem ser assuntos, reconhecidas a partir do contexto. Cita como exemplo o Partido Comunista da Finlândia, The Communist Party of Finland ("Suomen Kommunistinen Puolue (19181944)"), que é considerado um Agente quando se inicia a descrição, mas que pode ser assunto quando se descrevem os documentos que tratam sobre ele e que foram arquivados pela agência de inteligência do país. O modelo afirma que assunto é sempre relacionado ao conteúdo dos documentos. 
A Espanha, desde 2007, com a criação da Comisión de Normas Españolas de Descripción Archivística (CNEDA), discute a normalização da descrição arquivística de forma a ampliar o acesso aos documentos. E, com a aprovação, também no ano de 2007, do documento intitulado Projeto NEDA-I (Normas Españolas de Descripción Archivística), estabeleceu objetivos nessa área para o período aproximado de 5 anos. Como resultado dos trabalhos da Comissão, em 2012 foi publicado o Modelo Conceptual de Descripción Archivística y Requisitos de Datos Básicos de las Descripciones de Documentos de Archivo, Agentes y Funciones, o qual define 6 entidades e seus relacionamentos, com base no Modelo EntidadeRelacionamento:

\section{Documentos de arquivo, Agente, Función y sus divisiones, Norma, Concepto, objeto o acontecimento, Lugar. A entidade Concepto, Objeto o Acontecimiento é definida como [...] ideas o nociones abstractas, cosas materiales, eventos o sucesos de que tratan los documentos de archivo. (COMISIÓN DE NORMAS.... 2012, p. 24).}

O modelo apresenta uma extensa lista do que essa entidade pode abranger, como por exemplo, conceitos relativos a campos do conhecimento, disciplinas, escolas de pensamento, filosofias, religiões, entre outros.

Por fim, o Modelo Conceitual 'Records in contexts: a conceptual model for archival description - RiC-CM', do Conselho Internacional de Arquivos (ICA), é desenvolvido desde 2012 pelo Expert Group for Archival Description (EGAD) e teve sua versão preliminar publicada em setembro de 2016 (Consultation Draft v. 0.1). O $\mathrm{RiC}-\mathrm{CM}$ busca integrar as quatro normas de descrição arquivística internacionais: ISAD (G), ISAAR (CPF), ISDFe ISDIAH e, em sua versão preliminar, aponta 14 entidades básicas: Record, Record Component, Record Set, Agent, Occupation, Position, Function, Function (Abstract), Activity, Mandate, Documentary Form, Date, Place, Concept/ Thing. A representação temática é contemplada especificamente na entidade Concept/Thing, entendida como "Qualquer ideia ou noção, objeto material, ou evento ou ocorrência que pode ser associada com, ou em alguns casos ser o assunto de, outras entidades." (INTERNATIONAL COUNCIL ON ARCHIVES - ICA, 2016, p.18, tradução nossa). E, ainda, insere uma nota de escopo para essa entidade, complementando, "Inclui todas as entidades $\mathrm{RiC}$, bem como as seguintes: conceitos abstratos; cultural movimentos, períodos e eventos nomeados; coisas nomeadas, objetos e obras; figuras lendárias, míticas ou fictícias, personagens ou seres." (INTERNATIONAL COUNCIL ON ARCHIVES - ICA, 2016, p.18). O modelo RiC$\mathrm{CM}$ deixa claro que qualquer entidade que seja assunto do documento poderá ser associada a ele na entidade conceito/objeto.

Temos que o modelo CMAD é mais objetivo na nomeação, "Subject: Concept or object". Os modelos CNEDA e RiC-CM apresentam elementos e ideias comuns, mas não nomeiam a entidade como 'subject'. O modelo RiC-CM diz que qualquer ideia ou noção, coisa material ou evento/ocorrência podem ser associados a outras entidades ou podem ser assunto dela, deixando claro que essa entidade representa o que é significativo no contexto da análise sem ser, necessariamente, assunto.

Entendemos que o modelo RiC-CM abarca as especificidades dos outros dois modelos, além de apresentar a entidade 'Concept/Thing' vinculada à proveniência e organicidade, assim, a entidade definida para representar o conteúdo nesse estudo é a instituída nesse modelo.

\subsection{Themas para representação temática de documentos arquivísticos}

A representação temática de documentos arquivísticos precisa levar em conta algumas especificidades da área, levantadas no estudo de Vital (2017) e que guiam nossas proposições em relação a thema em documentos arquivísticos. Essa representação deve:

a) contemplar o Princípio da Proveniência e a característica da Organicidade;

b) ser realizada no contexto da Classificação e Descrição Arquivística; e

c) estar vinculada aos níveis de descrição.

Partindo dessas especificidades da representação temática de documentos arquivísticos e das entidades apresentadas pelos modelos conceituais de Descrição Arquivística, é possível relacioná-las. Cook (2012, p.142), analisando a arquivologia na pós-modernidade, 
afirma que a proveniência mudará de um "único lugar de origem, numa estrutura organizacional hierárquica tradicional", para aparecer "[...] vinculada à função e à atividade em vez da estrutura e o lugar". Para a construção da relação entre especificidades dos documentos arquivísticos e entidades do FRSAD, percebese a importância de caracterizar Proveniência e Organicidade. Assim, partindo da análise das entidades dos modelos conceituais apresentados, verifica-se que as que expressam ou auxiliam na caracterização da proveniência e da organicidade dos documentos são: Agente, Função, Atividade, Data e Lugar. Além dessas, outra entidade selecionada foi, como já citado, 'Concept/Thing', que apresentaremos traduzida, 'Conceito/Objeto', que representa o conteúdo do documento e deriva da análise da proveniência e da organicidade, ou seja, do conjunto de entidades que as caracterizam, conforme Figura 5.

Figura 5: Entidades que expressam Proveniência e Organicidade

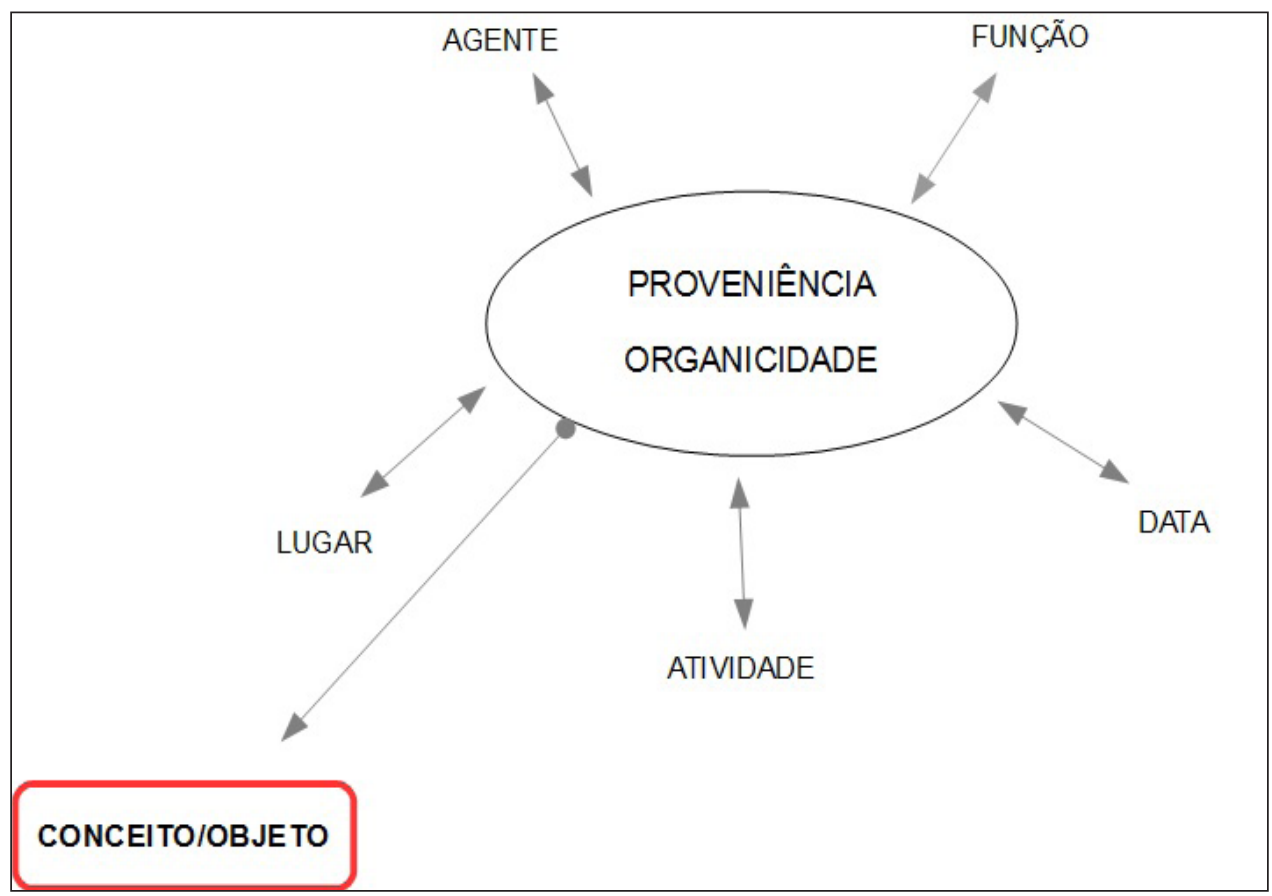

Fonte: elaboração do autor

As definições das entidades adotadas nessa pesquisa seguem o modelo RiC-CM pelo fato de ser um modelo internacional, que considerou contextos de diferentes países e outros modelos conceituais para descrição arquivística existentes. De acordo com esse modelo (INTERNATIONAL COUNCIL ON ARCHIVES - ICA, 2016), as entidades são:

a) Agente: Uma pessoa ou grupo, ou uma entidade criada por uma pessoa ou grupo, que é responsável por ações tomadas e seus efeitos.

b) Função: Um objetivo a longo prazo, propósito ou meta de um Agente.

c) Data: Informação cronológica associada com uma entidade que contribui para sua identificação e contextualização.

d) Atividade: Um conjunto de ações coordenadas ou transações executadas por um Agente em cumprimento de uma Função, ou na busca de uma Ocupação.

e) Lugar: Jurisdição ou qualquer ponto geográfico ou administrativo ou área.

f) Conceito/Objeto: Qualquer idéia ou noção, objeto material, ou evento ou ocorrência que pode ser associada com, ou em alguns casos ser $\circ$ assunto de, outras entidades.

Na Arquivologia, por vezes, há uma confusão entre assunto e função, é importante distingui-los. Para Tessitore (1989), assunto diz respeito 
às divisões artificiais derivadas da classificação das áreas do conhecimento, referindo-se sobre o que tratam os documentos. Já a função, refere-se às atribuições próprias ou naturais de uma instituição ou pessoa, visando cumprir um objetivo com a criação de um documento, atrelando, assim, os tipos documentais à determinada finalidade.

Partindo dessa caracterização, é possível definir com maior propriedade a representação temática do documento arquivístico, dada pela entidade 'Conceito/Objeto'.

No FRSAD os três grupos, Obra, Autoridade e Assunto, podem ser thema de um conjunto documental, isto é, expressam sua temacidade e apresentam uma designação por meio de um nomen. Denominou-se 'conjuntos documentais' ao invés de obra, como no modelo FRSAD, pelo fato de que nos arquivos os documentos são agrupados e existem em conjuntos, e são eles que permitem a compreensão dos documentos, mesmo quando a análise se der no nível da 'peça'.

Assim, com base no modelo FRSAD e relacionando-o com as especificidades do documento arquivístico, propõem-se as entidades apresentadas na Figura 6 para a representação temática dos conjuntos documentais.

Figura 6: Entidades que podem ser Thema em documentos arquivísticos

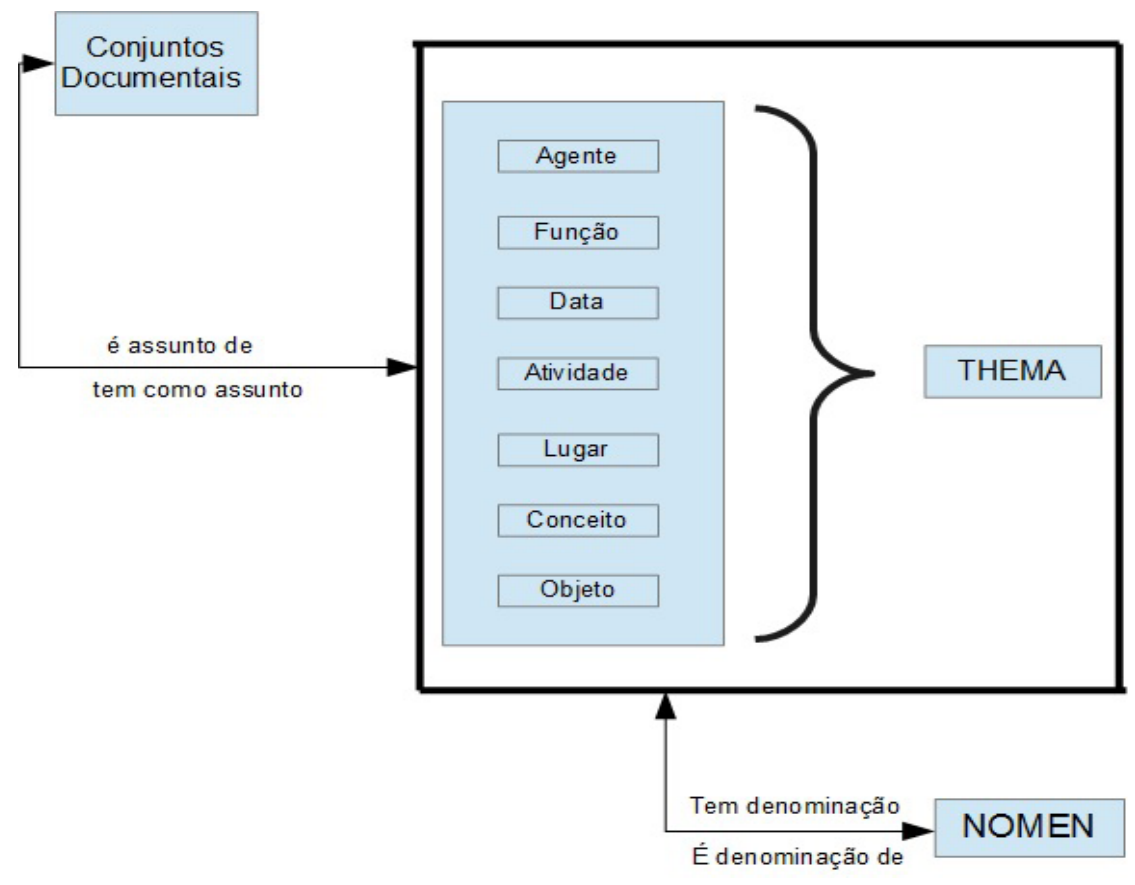

Fonte: Com base em IFLA (2010, p.15)

É importante frisar que cada um dos themas atribuídos tem uma designação dada por um nomen que pode ou não estar vinculado a uma linguagem documentária.

A representação temática da informação de documentos arquivísticos precisa estar vinculada às funções de Classificação e Descrição Arquivística e, consequentemente, respeitar a descrição multinível, ou seja, a descrição dos diferentes conjuntos documentais, como Fundo, Série, Processo, Peça, entre outros definidos em cada contexto. Qualquer uma das entidades citadas pode representar o conteúdo de um conjunto documental, porém, cada uma tem sua pertinên- cia em decorrência do nível analisado. Assim, construíram-se categorias de themas pertinentes a cada um dos principais níveis de descrição estabelecidos na ISAD (G): Fundo, Série, Processo e Peça ${ }^{2}$, representadas na Figura 7.

Os níveis de descrição são variáveis e estão relacionados ao Plano de classificação adotado, seguindo o princípio da Organicidade, do geral para o específico.

\footnotetext{
2 Seguiu-se a nomenclatura utilizada na Norma Internacional (ISAD (G), 2000), mas a Norma Brasileira, NOBRADE (Conselho Nacional de Arquivos, 2006) utiliza o termo 'item documental', sendo essa uma adaptação da ISAD (G) se pressupôs que o sentido de peça é o mesmo que item documental.
} 
Figura 7 - Relação entre Thema e níveis de Descrição Arquivística
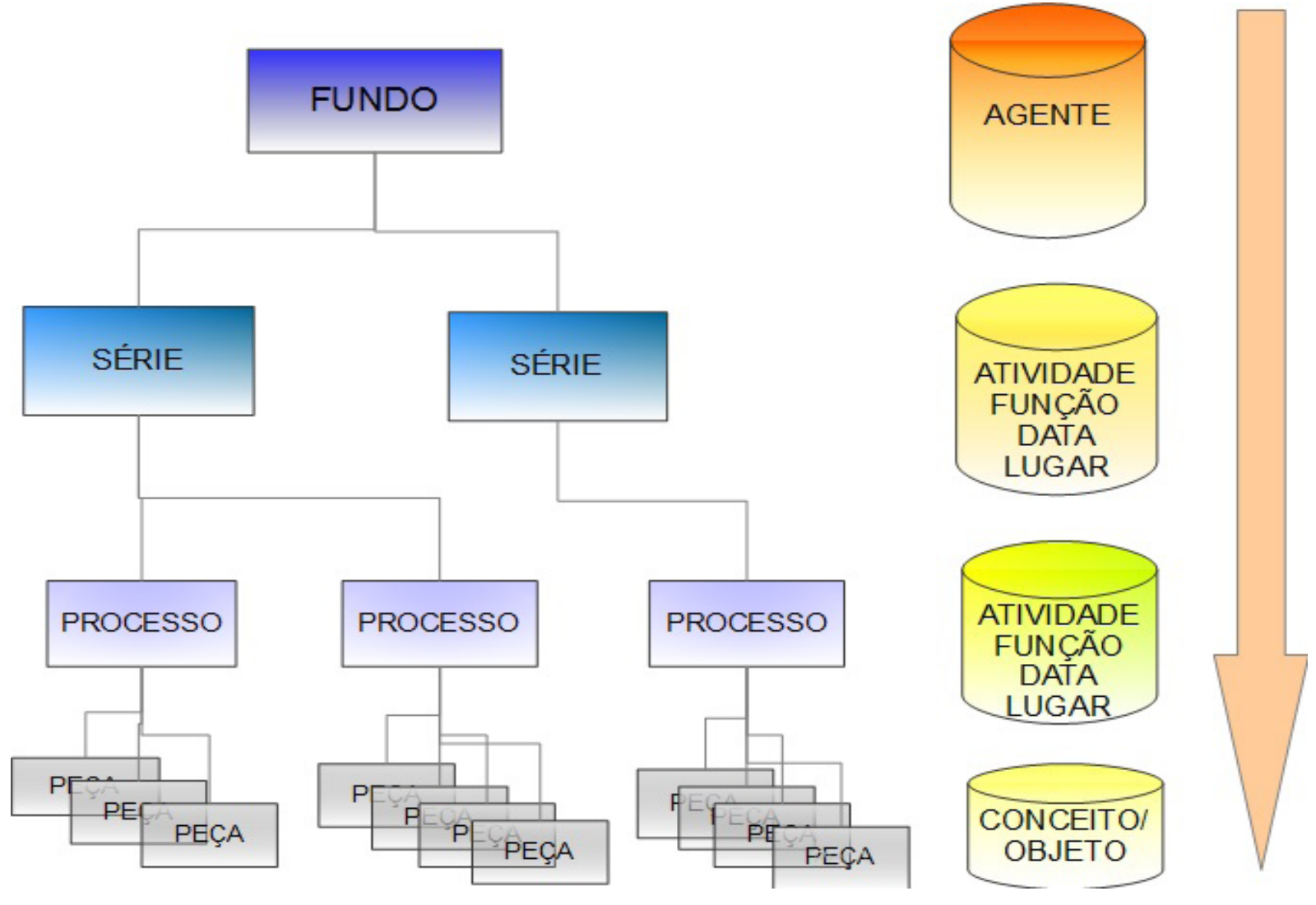

Fonte: elaboração do autor

Os níveis de descrição são estabelecidos de forma hierárquica e orgânica, ou seja, do mais abrangente ao mais específico e mantendo relação entre eles. Uma peça só será representada adequadamente quando analisada a estrutura hierárquica da qual faz parte. $\quad O$ princípio da representação temática relacionada com os níveis é de que quanto mais específico for o nível de descrição, mais específicas serão as entidades a serem representadas. Com base na Descrição Arquivística, podem ser atribuídas as entidades condizentes com cada nível, de acordo com o quadro 1. O nível fundo, por ser abrangente, tem somente a entidade 'Agente' como representante temático, por ser o elemento que o constitui. No entanto, não é necessariamente a única entidade que poderá ser atribuída na representação temática desse conjunto documental.
Quadro 1: Níveis de descrição arquivística e Entidades

\begin{tabular}{|c|c|}
\hline $\begin{array}{c}\text { NÍVEL DE DESCRIÇÃO } \\
\text { ARQUIVÍSTICA }\end{array}$ & $\begin{array}{c}\text { ENTIDADE QUE } \\
\text { REPRESENTA O } \\
\text { CONTEÚDO }\end{array}$ \\
\hline FUNDO & AGENTE \\
\hline SÉRIE & ATIVIDADE \\
& FUNÇÃO \\
& DATA \\
& LUGAR \\
\hline PROCESSO & ATIVIDADE \\
& FUNÇÃO \\
& DATA \\
& LUGAR \\
\hline PEÇA & CONCEITO/OBJETO \\
\hline
\end{tabular}

Fonte: elaboração do autor 
Para que a entidade 'Conceito/Objeto' seja representada, as entidades anteriormente atribuídas precisam ser consideradas. Qualquer um dos níveis de descrição pode ter a representação de qualquer uma das entidades, ou seja, conceito/objeto é pertinente desde o nível do Fundo até a Peça. Porém, para que seja caracterizado com precisão, é necessário que o conjunto de entidades tenha sido identificado. Assim, a representação temática de documentos arquivísticos abrange o conjunto das entidades: Agente, Atividade, Função, Data e Lugar, vinculadas pelos níveis.

O conjunto de Entidades definido tem como principal ponto a caracterização da Proveniência e da Organicidade para que a análise temática, foco específico da entidade 'Conceito/ Objeto', seja identificada com maior precisão e especificidade. Esse conjunto de entidades para representação temática permite a criação de relações significativas e dinâmicas entre os conjuntos documentais, a partir da análise contextual. Essa possibilidade faz com que a representação esteja mais próxima da dinamicidade das transformações pelas quais os documentos passam desde a produção. As conexões de entidades permitem que a proveniência seja múltipla, assim como as funções e atividades vinculadas aos documentos arquivísticos. Ilimitados documentos e seus conjuntos estão conectados sem necessariamente dividirem o mesmo espaço físico, ou mesmo existirem fisicamente.

\section{CONSIDERAÇÕES FINAIS}

O aprofundamento conceitual e o diálogo com outras áreas do conhecimento fortalece a ciência arquivística para alicerçar suas bases e avançar nas proposições sobre a Organização e Representação da Informação e do Conhecimento nos arquivos.

Essa pesquisa tem como pressuposto o fato de que documentos em arquivos apresentam especificidades que os diferenciam dos documentos em outros serviços de informação. A análise temática nos arquivos deriva da análise do conjunto documental, portanto, contextualizar é fundamental, pois um documento só é o que é nas relações que estabelece com os outros documentos. A análise isolada leva à perda de informações significativas sobre ele. Esse fato foi evidenciado na análise das entidades dos modelos conceituais para DA, que levaram à proposição de Themas que caracterizam a temática de um documento em arquivo.

Foram mapeadas as entidades e atributos relacionados à representação temática nos modelos conceituais para descrição arquivística, quais sejam: AGRkMS, Technical Specifications for the Electronic Recordkeeping Metadata Standard, CMAD, CNEDA e Records in Context - CIA. Dos quatro modelos analisados, três deles, CMAD, CNEDA e RiC-CM, apresentam uma entidade específica para representar o conteúdo do documento. Como frisado, a representação temática em arquivos é dependente de uma análise contextual ampla, que perpassa as entidades que expressam ou auxiliam na caracterização da proveniência e da organicidade dos conjuntos documentais, quais sejam: Agente, Função, Atividade, Data e Lugar. A partir desse conjunto de entidades, chega-se ao 'Concept/Thing', traduzida para 'Conceito/Objeto', que representa a temática do documento e deriva da análise da proveniência e da organicidade, ou seja, do conjunto de entidades que as caracterizam. Como já citado, qualquer uma das entidades, Agente, Função, Atividade, Data, Lugar e Conceito/Objeto, poderá representar o conteúdo dos conjuntos documentais, porém, cada uma tem sua pertinência em decorrência do nível analisado. Assim, construíram-se categorias de themas pertinentes a cada um dos principais níveis de descrição estabelecidos na ISAD (G): Fundo, Série, Processo e Peça. .É importante destacar que os níveis de descrição citados são apenas ilustrativos da estrutura derivada do plano de classificação, que é condizente com as características de cada contexto. E, seguindo o modelo FRSAD, após a identificação das entidades que caracterizam a representação temática, é feita a designação através do nomen, momento em que é recomendável o uso de linguagens documentárias.

Esperamos que os resultados da pesquisa deixem uma contribuição para a representação temática em arquivos, numa perspectiva de integração de diferentes sistemas de informação, em que as especificidades são preservadas, mas não invalidam a centralização da recuperação da informação. Nesse sentido, pesquisas que objetivem a integração técnica de sistemas de recuperação de diferentes serviços de informação são importantes na concretização dessa perspectiva. 
Artigo recebido em 19/02/20I6 e aceito para publicação em I2/03/20I8

\title{
FRSAD MODEL AS A BASIS FOR THE THEMATIC REPRESENTATION IN THE ARCHIVISTIC DESCRIPTION ACTIVITY
}

\begin{abstract}
The organization and representation of information in the archives has been gaining space for discussion in the literature of Information Science, especially after the automation of the information systems. The conceptual models, supported by the entity/relationship perspective, which are based on models developed in automated environments and present the feasibility of dynamic semantic relationships, such as the Family of Functional Requirements (FR family), provide a perspective for this environment. This research considers that the documents in archives have specificities that differentiate them from the documents in other information services, Organic units and Provenience, and therefore, the subject representation of these documents also presents peculiarities that must be considered. Starting from Organic units and Provenience, this study aims to establish the themas for these documents, based on the FRSAD conceptual model of the FR family. It presents as methodological procedures the bibliographic research, for the mapping and identification of the representative entities of the subject present in the conceptual models for Archival Description, corelating them to the specifics. Five conceptual models were identified, three of them have specific entities to represent the content of documents. From the set of entities analyzed, we arrive at the 'Concept / Object', which represents the document's theme and derives from the analysis of provenience and organic, ie, the set of entities that characterize them, Agent, Function, Activity, Date and Place. It is concluded that the conceptual models for subject representation are pertinent and collaborate in establishing multiple relationships between documentary sets in archives.
\end{abstract}

Keywords: Conceptual models. Subject representation. Archival description.

\section{REFERÊNCIAS}

CHEN, P. P-S. The Entity-relationship model - A basis for the enterprise view of data. Massachusetts Institute of Technology. 1977. Disponível em:< http://delivery.acm. org/10.1145/1500000/1499421/p77-chen.pdf.>. Acesso em: 01 abr. 2016.

COMISIÓN DE NORMAS ESPAÑOLAS DE DESCRIPCIÓN ARCHIVÍSTICA. Modelo Conceptual de Descripción Archivística y Requisitos de Datos Básicos de las Descripciones de Documentos de Archivo, Agentes y Funciones. Sevilla, Espanha, 2012.

CONSELHO NACIONAL DE ARQUIVOS. NOBRADE: Norma Brasileira de Descrição arquivística. Rio de Janeiro: Arquivo Nacional, 2006. Disponível em: <http://www.conarq. arquivonacional.gov.br/Media/publicacoes / nobrade.pdf.>. Acesso em: 04 jul. 2012.
COOK, Terry. Arquivologia e pós-modernismo: novas formulações para velhos conceitos. Informação arquivística, Rio de Janeiro, RJ, v.1, n.1, p.123-148, jul./ dez. 2012.

GUEGUEN, Gretchen; et al. Para um modelo conceitual internacional de descrição arquivística. Acervo, Rio de Janeiro, v.26, n.2, p.100-116, jul./ dez. 2013.

IFLA Study Group on the Functional Requirements for Bibliographic Records. Functional requirements for bibliographic records: final report. München : K. G. Saur, 1998.

IFLA Working Group on the Functional Requirements for Subject Authority Records. Functional Requirements for Subject Authority Data (FRSAD): a conceptual model. Berlin: IFLA, 2010. Disponível em: <http://www.ifla. org/files/assets/classification-and-indexing/ functional-requirements-for-subject-authority- 
data/frsad-final-report.pdf> Acesso em: 21 mar. 2016.

INTERNATIONAL COUNCIL ON ARCHIVES - ICA. ISAD(G): norma internacional de descrição arquivística. 2.ed. Rio de Janeiro: Arquivo Nacional, 2000. (Publicações técnicas, n. 49). Disponível em: http://www.conarq. arquivonacional.gov.br/Media/publicacoes/ isad_g_2001.pdf. Acesso em: 04 jul. 2012.

Experts group on archival description. Records in contexts: a conceptual model for archival description. September, 2016. Disponível em: $\quad$ http://ica-egad.org/ric/conceptualmodel/RiC-CM-0.1.pdf. Acesso em: 15 set. 2016. Consultation Draft $v 0.1$.

MELO, Maria Antônia Fonseca. Contribuições das abordagens positivista e pragmática do estudo do conceito para o modelo conceitual FRSAD. 2013. 133f. Dissertação (Mestrado em Ciência da Informação)-Universidade de Brasília, Brasília, 2013.

MORENO, Fernanda Passini; ARELLANO, Miguel Angel Mardero. Requisitos funcionais para registros bibliográficos - FRBR: uma apresentação. Revista Digital de
Biblioteconomia e Ciência da Informação, Campinas, v .3, n 1, p. 20-38, jul./dez. 2005.

NATIONAL ARCHIVES (Austrália). Australian Government Recordkeeping Metadata Standard Version 2.0. Austrália, 2008.

NATIONAL ARCHIVES (New Zealand). Technical Specifications for the Electronic Recordkeeping Metadata Standard: version 1.0. Nova Zelandia, 2008.

NATIONAL ARCHIVES (Finlândia). Finnish Conceptual model for archival description. Finlândia, 2013.

RIVA, Pat; ZUMER, Maja. Introducing the FRBR Library Reference Model. In.: IFLA World Library and Information Congress, 81., 2015, Cape Town, Africa do Sul. Anais...Cape Town, Africa do Sul, 2015. Disponível em: http:// library.ifla.org/1084/. Acesso em: 30 jan. 2016.

VITAL, Luciane Paula. Representação temática de documento arquivístico: as contribuições do modelo conceitual FRSAD. 2017. 191p. Tese (Doutorado e Ciência da Informação) - Universidade Federal de Santa Catarina, Florianópolis, 2017. 
